Explanation of Plate VI.

Figure 1. Clasper of Boletina gronlandica.

Figure 2. Hypopygium of Allodia ornaticollis.

Figure 3. Hypopygium of Exechia aviculata.

Figure 4. Hypopygium of Exechia pollex.

Figure 5. Lateral view of clasper of Rhymosia triangularis. A, arm of clasper.

Drawings made by D. B. Creager.

\title{
A NEW NAME FOR LITHOMYRMEX CARP. (HYMENOPTERA)
}

In my revision of the fossil ants (Bull. Mus. Comp. Zoöl., 70 (1) : p. 36), which was published in January, 1930, I established the myrmicine genus Lithomyrmex for two species, rugosus and striatus, from the Miocene shales of Florissant, Colorado. Unfortunately, the same generic name was used by Dr. J. Clark a few months earlier for a recent species of ant, glauerti, from West Australia (Journ. Roy. Soc. W. Australia, 14: p. 36, 1929). I therefore propose the new name Eulithomyrmex for Lithomyrmex Carp. (nec Lithomyrmex Clark, 1929), to include the two extinct species from the Florissant shales-F. M. Carpenter. 

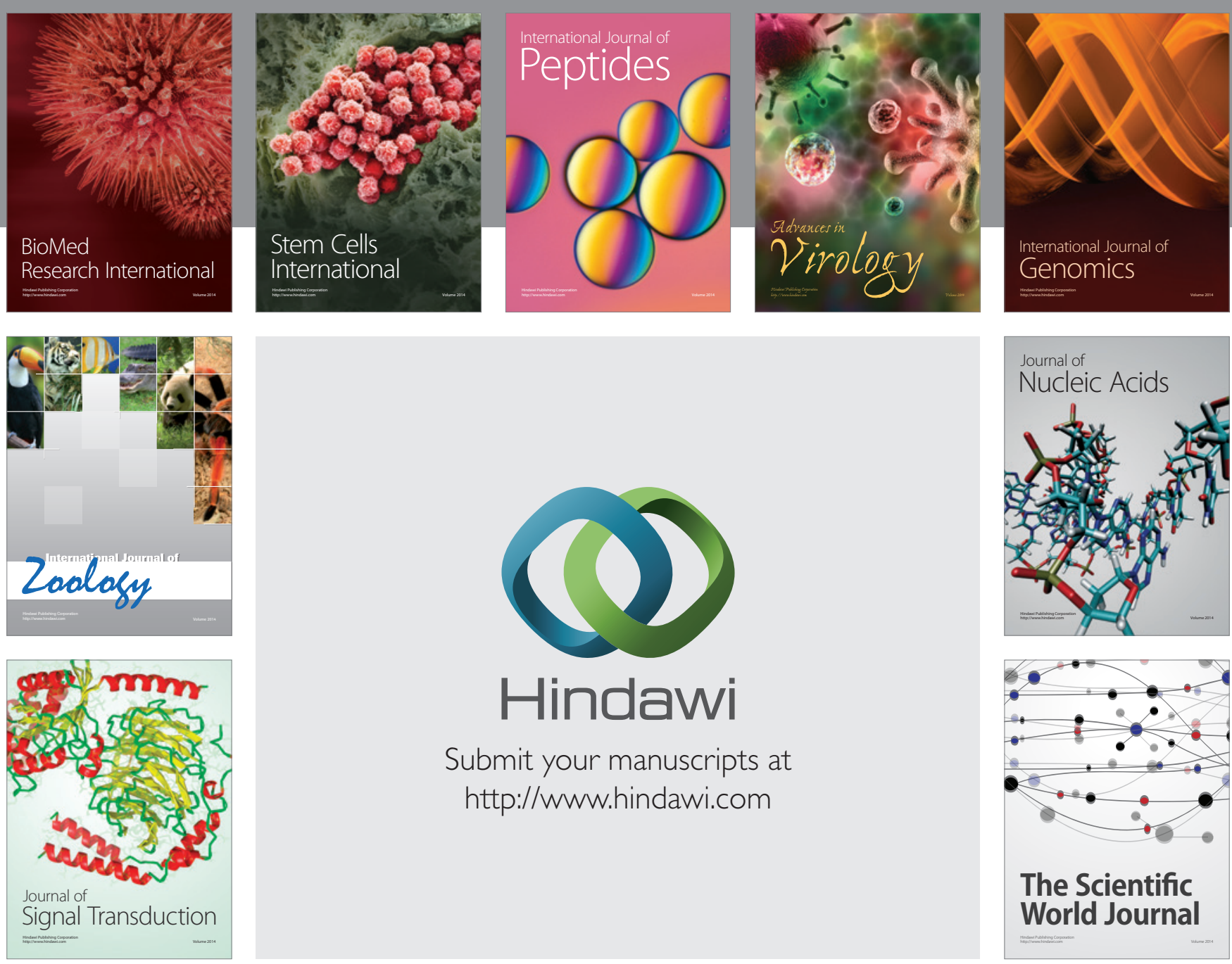

Submit your manuscripts at

http://www.hindawi.com
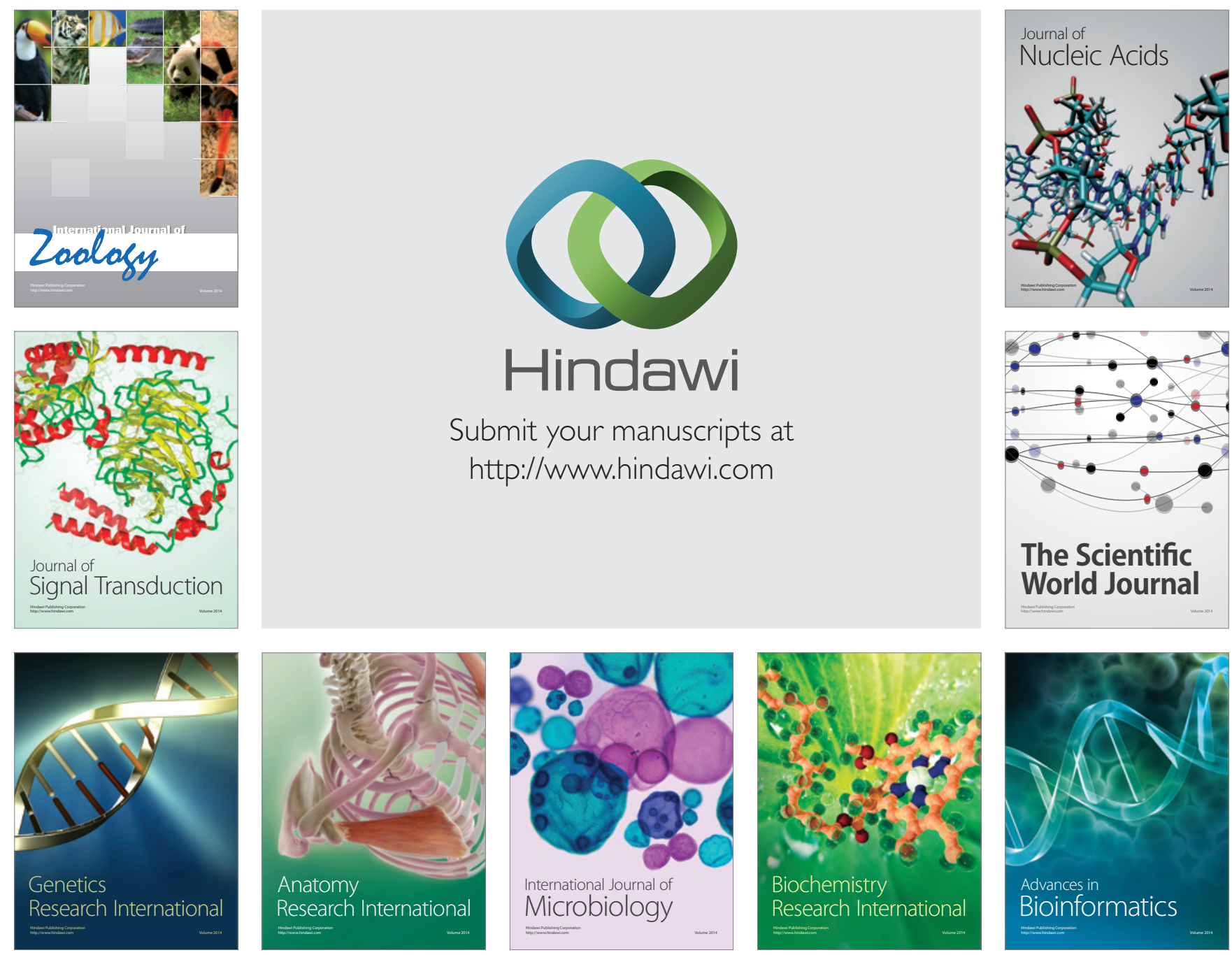

The Scientific World Journal
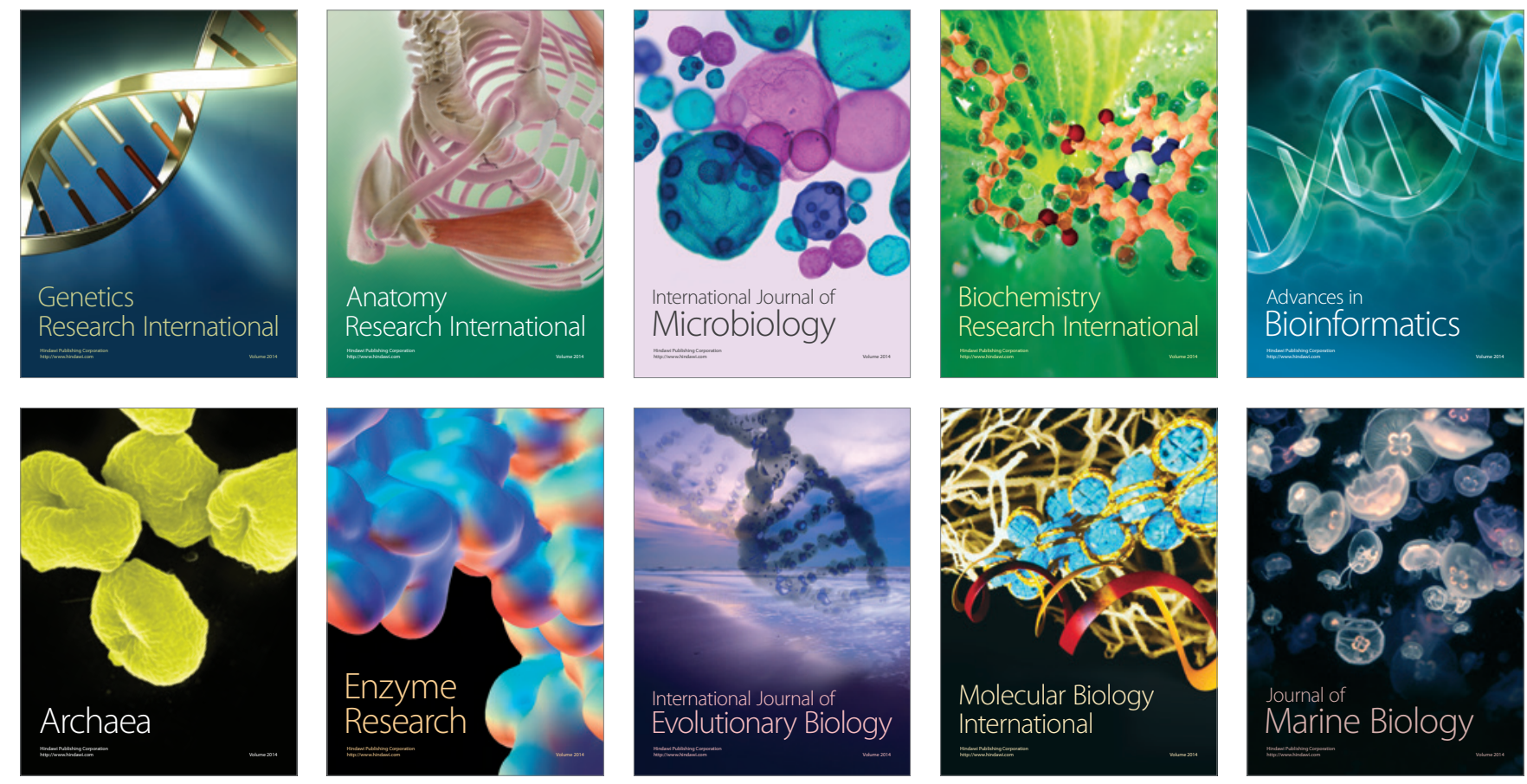